\title{
Elevated Medical Costs for Obese Fifth Graders in California and Texas
}

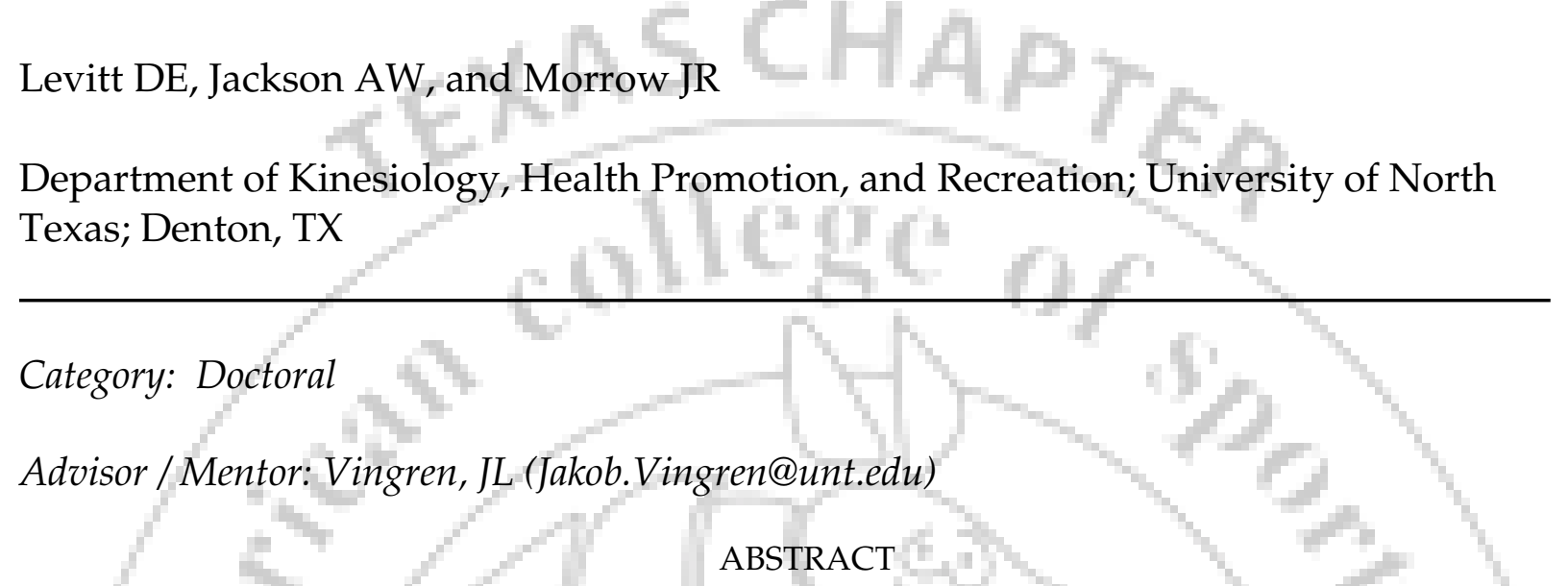

Finkelstein et al. (2014) estimated that an obese ten-year-old, typically in the fifth grade, will incur between $\$ 12,660$ and $\$ 19,630$ in direct medical costs beyond those of a normal-weight ten-year-old over a lifetime. PURPOSE: The purpose was to estimate the lifetime direct medical costs attributable to obesity for fifth graders in the two most populous states, Texas and California. METHODS: Body composition data from the Presidential Youth Fitness Program's FITNESSGRAM ${ }^{\circ}$ administered in California and Texas each school year from 2010 - 2011 to 2012 - 2013 were used. Data included information on 447,619-456,409 fifth graders each year in California and 296,887 - 337,514 fifth graders in Texas. The number and percentage of students in each of the FITNESSGRAM ${ }^{\circledR}$ body composition categories was calculated and those in the Needs Improvement - High Risk (NI - HR) were used for cost estimation. The number of students in the NI - HR category for each year in each state was multiplied by the recommended cost estimate of $\$ 19,000$ to project the elevated lifetime medical costs attributable to obesity for each group of fifth graders in each state. RESULTS: More than 33\% of fifth graders in California and more than $36 \%$ of fifth graders in Texas were categorized as NI - HR each year over the 3-year period. Results indicate that the increased lifetime direct medical costs due to obesity will be nearly $\$ 3$ billion for each group of fifth graders in California and more than $\$ 2$ billion for each group of fifth graders in Texas. CONCLUSIONS: When the percentage of obese fifth graders is extrapolated to the entire United States' 4 million 10-yearolds, this results in more than $\$ 25$ billion in elevated direct lifetime medical costs attributable to obesity for this 1-year age cohort. These estimates are for obesity and do not include the additional costs associated with overweight (i.e., FITNESSGRAM® Needs Improvement - Some Risk category). This information should be used to influence spending decisions and resource allocation to obesity reduction and prevention efforts.

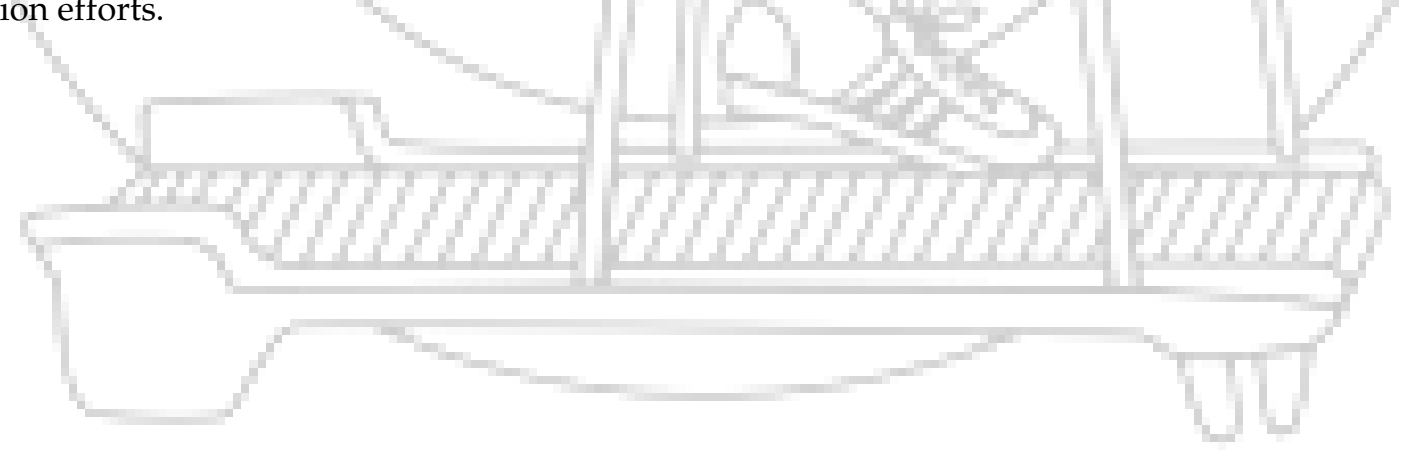

